\title{
Relationship Between CA 19.9 and the Lewis Phenotype: Options to Improve Diagnostic Efficiency
}

\author{
MARINA PARRA-ROBERT ${ }^{1}$, VÍCTOR MOLINA SANTOS ${ }^{2}$, SILVIA MIRÓ CANIS ${ }^{3}$, \\ XAVIER FILELLA PLA ${ }^{1}$, JOSEP MARIA AUGÉ FRADERA ${ }^{1}$ and RAFAEL MOLINA PORTO ${ }^{1}$ \\ ${ }^{1}$ Oncobiology Unit, Department of Biochemistry and Molecular Genetics, \\ Biomedical Diagnostic Center (CDB), Hospital Clínic, Barcelona, Spain; \\ ${ }^{2}$ Department of Surgery, Hospital Clínic, Barcelona, Spain; \\ ${ }^{3}$ Consorci Laboratori Intercomarcal, Vilafranca del Penedés, Spain
}

\begin{abstract}
Background/Aim: Approximately 10\% of patients are unable to synthesize CA 19.9 (Lewis-negative), and these results are erroneously considered false-negatives. The aim of this study was to confirm that CA 19.9 cannot be detected by immunoassays in Lewis-negative patients. Materials and Methods: CA 19.9 levels were measured by immunological assays and Lewis phenotype was determined by the haemagglutination reaction. Results: Patients with Lewis phenotype $(a+b-)$ or $(a-b+)$ had significantly higher $C A$ 19.9 levels than Lewis-negative patients with active cancer $(p<0.001)$, no-evidence of disease $(N E D)$ patients $(p<0.001)$ or patients with benign disease $(p<0.001)$. Ninenty-four percent of patients (33/35) with undetectable CA 19.9 had a Lewis-negative phenotype. Additionally, 94.7\% (34/36) of patients with Lewis-negative phenotypes had undetectable CA 19.9 serum levels. Conclusion: Patients with undetectable CA 19.9 serum levels tend to be Lewis-negative, and CA 19.9 is not useful in diagnosis or follow-up.
\end{abstract}

Carbohydrate antigen 19.9 (CA 19.9), or monosialylated Lewis is a sialyl-Lewis ${ }^{\mathrm{A}}$ blood group antigen $\left(\mathrm{Le}^{\mathrm{a}}\right)(1)$ that is clinically used as a tumour marker (TM), primarily in patients with gastrointestinal cancer, especially pancreatic or cholangiocarcinoma (2-7). However, this TM is not specific to gastrointestinal malignancies, as increased levels have been observed in other tumours, such as ovarian mucinous carcinoma, endometrial cancer or lung cancer (8-10). Likewise, false-positive CA 19.9 results may be observed in

Correspondence to: Rafael Molina, MD, Biochemistry and Molecular Genetics Department, Hospital Clinic, Villarroel, 170, 08036 Barcelona, Spain. Tel: +34 629392985, e-mail: RMOLINA@clinic.cat

Key Words: CA 19.9, Lewis, pancreatic cancer, cholangiocarcinoma, false negative results. certain benign diseases that are mainly associated with hepatobiliary-pancreatic diseases (e.g., pancreatitis, renal failure, and mucinous cysts) (2,11-14).

CA 19.9 is a TM that is suggested to help in the diagnosis of pancreatic cancer, primarily in patients with jaundice, as well as in therapy monitoring. The sensitivity of CA 19.9 in pancreatic cancer is approximately $70-90 \%$ and is related to tumour stage and the Le phenotype $(2,15-17)$. There are three Le blood phenotypes, depending on the presence or absence of the Le antigenic epitopes, $\mathrm{Le}^{\mathrm{a}}$ and $\mathrm{Le}^{\mathrm{b}}: \mathrm{Le}(\mathrm{a}-\mathrm{b}-), \mathrm{Le}(\mathrm{a}-\mathrm{b}+)$ and $\operatorname{Le}(\mathrm{a}+\mathrm{b}-)(15)$. Patients with the $\operatorname{Le}(\mathrm{a}-\mathrm{b}-)$ phenotype (10\% of patients) are unable to synthesize CA 19.9 and, as a result, are being erroneously considered TM-negative when pancreatic cancer or other malignancies are present (falsenegatives) (18). Likewise, the use of CA 19.9 in the followup will be also erroneously interpreted in these Lewis-negative patients, because it will be always negative independently of the patient's condition. The early identification of Lewisnegative patients will improve the use of this marker, avoiding false-negative results and increasing sensitivity in those that are able to release it.

The aims of this study were: i) Confirm that CA 19.9 cannot be detected in $\mathrm{Le}(\mathrm{a}-\mathrm{b}-)$ patients, independently of the pathology studied and whether the tumour isbenign or malignant. ii) Evaluate the possible relationship between the CA 19.9 serum levels determined by immunological assays and Le phenotypes. iii) evaluate CA 19.9 serum levels in serial dilutions and confirm that the relationship with the Le phenotype is not modified.

\section{Materials and Methods}

The study included 42 patients with benign diseases, 28 patients with cancer, but no evidence of disease (NED) after radical treatment, and 53 patients who had active cancer. Patients with benign diseases included 10 patients with pancreatic diseases, 7 with gynaecological diseases, 6 with pulmonary diseases, 3 with gastrointestinal diseases, 3 with liver diseases, and 13 with other 
Table I. Distribution of clinical data within CA 19.9 concentration groups.

\begin{tabular}{|c|c|c|c|c|}
\hline & \multicolumn{4}{|c|}{ CA 19.9 concentration $(\mathrm{U} / \mathrm{ml})$} \\
\hline & Undetectable & $3-<7$ & $7-37$ & $>37$ \\
\hline \multicolumn{5}{|l|}{ Total } \\
\hline of patients & 35 & 25 & 30 & 33 \\
\hline Active cancer & $13(37.15 \%)$ & $7(28.00 \%)$ & $8(26.70 \%)$ & $25(75.80 \%)$ \\
\hline Pancreatic cancer & 3 & - & 2 & 14 \\
\hline Intestinal cancer & 2 & 1 & 1 & - \\
\hline Lung cancer & 4 & 1 & 2 & 3 \\
\hline Endometrial cancer & - & 1 & - & 2 \\
\hline Gastric cancer & - & 1 & 2 & 1 \\
\hline Cholangiocarcinoma & - & - & - & - \\
\hline Others & 4 & 3 & 1 & 5 \\
\hline Non-active cancer & $9(25.70 \%)$ & $6(24.00 \%)$ & $9(30.00 \%)$ & $4(12.10 \%)$ \\
\hline Pancreatic cancer & - & - & 1 & 1 \\
\hline Intestinal cancer & 1 & 1 & 1 & 1 \\
\hline Lung cancer & - & - & 1 & - \\
\hline Endometrial cancer & 5 & 1 & 1 & 1 \\
\hline Gastric cancer & 1 & 2 & 5 & - \\
\hline Cholangiocarcinoma & 1 & - & - & 1 \\
\hline Others & 1 & 2 & - & - \\
\hline Benign & $13(37.15 \%)$ & $12(48.00 \%)$ & $13(43.30 \%)$ & $4(12.10 \%)$ \\
\hline Pancreatic disease & 5 & 3 & 2 & - \\
\hline Hepatic disease & - & 1 & 2 & - \\
\hline Gastric disease & - & 1 & - & 1 \\
\hline Pulmonary disease & 1 & 1 & 2 & 2 \\
\hline Intestinal disease & 1 & - & - & - \\
\hline Gynaecologic disease & 3 & 1 & 2 & 1 \\
\hline Others & 3 & 5 & 5 & - \\
\hline
\end{tabular}

benign diseases. Patients with NED included 8 patients with gastric cancer, 8 patients with endometrial cancer, 4 with intestinal cancer, 4 with pancreatic cancer or cholangiocarcinoma, one with lung cancer and 3 with other types of cancer. NED was confirmed at least 12 months after sample determination. Patients with active cancer included 19 patients with pancreatic cancer (11 stage IV, 8 stage III), 10 with lung cancer ( 7 stage IV, 3 stage III), 4 with gastric cancer (stage IV), 4 with intestinal cancer (stage II-III), 3 with endometrial cancer (stage II) and 13 with other types of cancer (11 stage IV, 2 stage III).

Blood samples, were collected by venous puncture in plasma EDTA K3 tube and serum gel separator tubes. After centrifugation, serum samples were taken for routine biochemistry evaluation of CA19.9, which was performed routinely using the autoanalyzer Elecsys $411^{\circledR}$ (Roche Diagnostics, Basel, Switzerland), considering $37 \mathrm{U} / \mathrm{ml}$ as the cut-off level. One aliquot of serum was preserved at $-20^{\circ} \mathrm{C}$ for future experiments. Once the patients were randomly selected, the plasma sample was used to study the Le phenotype by a haemagglutination reaction using anti-Lewisa and anti-Lewisb monoclonal antibodies (Sanquin Plesmanlaan, Amsterdam, Netherlands). Patients were classified into Le phenotype groups: $\mathrm{Le}(\mathrm{a}-\mathrm{b}-)$, Le(a-b+) and $\mathrm{Le}(\mathrm{a}+\mathrm{b}-)$.

Clinical data, including diagnosis, type of cancer, stage of cancer, presence of effusion and analytical information (creatinine, total bilirubin, gamma-glutamyl transpeptidase, aspartate aminotransferase, alanine aminotransferase and carcinoembryonic antigen) were registered in all of the patients included in our study. In addition, we collected the CA 19.9 results retrospectively in (serial determination) $28 \mathrm{Le}(\mathrm{a}-\mathrm{b}-)$ patients, $47 \mathrm{Le}(\mathrm{a}-\mathrm{b}+)$ patients and $18 \mathrm{Le}(\mathrm{a}+\mathrm{b}-)$ patients. Patients with cancer were classified according to the TNM classification (19). This protocol was approved by the Ethical Committee of the Hospital Clinic. The laboratory has a total quality management system and was certified with ISO 9001:2015 standards by AENOR (Asociacion Española de Normalización y Certificación, Spain).

Statistical methods. The Kruskal-Wallis test and Mann-Whitney test were used to compare the CA 19.9 levels between the Le phenotype groups. Box-plot graphs were also generated. Statistical significance was set at a $p$-value of less than 0.05 . Statistical analysis was performed using IBM SPSS Statistics version 20 (SPSS, Inc, Chicago, IL, USA).

\section{Results}

CA 19.9 results obtained in the different groups of patients are shown in Table I. Abnormal CA 19.9 serum levels (>37 U/ml) were found in 33 of the 123 (26.8\%) patients, 


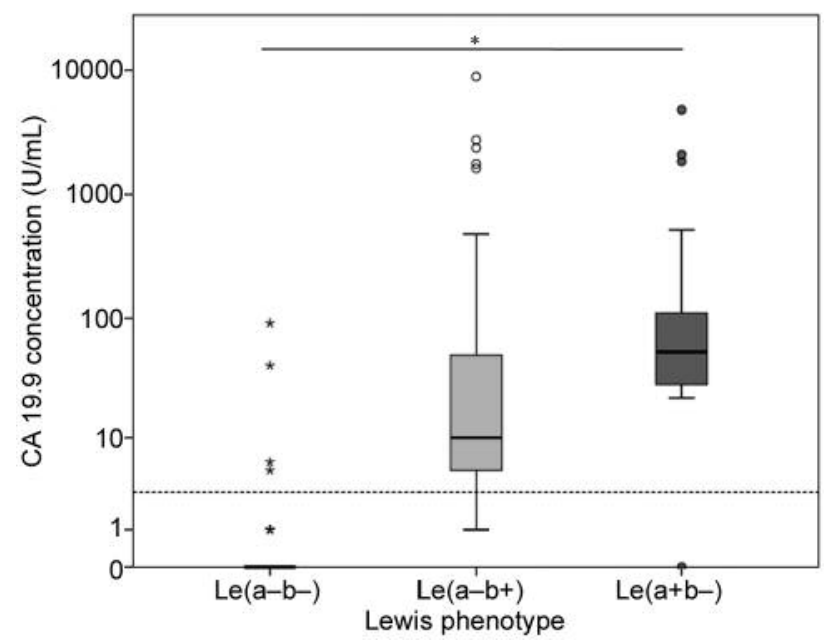

Figure 1. Box-plot between the CA 19.9 concentration and the Lewis phenotype. Dotted line shows the functional sensitivity of CA 19.9 determination $(3 \mathrm{U} / \mathrm{ml})$. *p-Value $<0.001$.

including 4 patients with benign diseases, 4 NED patients and 25 patients with active cancer. Significantly higher CA 19.9 concentrations were observed in patients with active cancer ((median (interquartile range); 28(4-220) U/ml) than in those patients with NED $(6(1-21) \mathrm{U} / \mathrm{ml})$ or in those with benign diseases $(5(0-24) \mathrm{U} / \mathrm{ml})(p<0.001)$.

The Lewis phenotype was Le(a-b-) in $36(29.3 \%)$ patients, $\mathrm{Le}(\mathrm{a}-\mathrm{b}+)$ in $63(51.2 \%)$ patients and $\mathrm{Le}(\mathrm{a}+\mathrm{b}-)$ in the remaining $24(19.5 \%)$ patients. Patients with $\mathrm{Le}(\mathrm{a}+\mathrm{b}-)$ had significantly higher concentrations of CA 19.9 (median (interquartile range); $53(28-114) \mathrm{U} / \mathrm{ml})$ compared to those with $\mathrm{Le}(\mathrm{a}-\mathrm{b}+)(10(5-67) \mathrm{U} / \mathrm{ml})(p<0.0001)$, and both had higher levels than the Le(a-b-) group $(p<0.001)$. A Box-plot between the CA 19.9 concentration and Lewis phenotype is depicted in Figure 1. Similar results were observed when patients were subdivided according to the Le phenotype and tumour stage; significantly higher CA 19.9 levels were found in active cancer than in benign or NED in both $\mathrm{Le}(\mathrm{a}-\mathrm{b}+)$ and $\mathrm{Le}(\mathrm{a}+\mathrm{b}-)(\mathrm{NED})(p<0.001)$ (Figure 2). Interestingly, there is a trend towards higher CA 19.9 serum levels in $\operatorname{Le}(a+b-)$ patients than in patients with the $\operatorname{Le}(\mathrm{a}-\mathrm{b}+)$ phenotype, but this finding was only significant in patients with non-active cancer (benign and NED) $(p=0.003)$ and not in patients with active cancer ( $p=0.153$ ) (Table II, Figure 2). These differences were not due to bilirubin concentrations, since they were similar in the $\mathrm{Le}(\mathrm{a}-\mathrm{b}+)$ (median (interquartile range); 0.7 (0.2$2.3) \mathrm{mg} / \mathrm{dl})$ and $\mathrm{Le}(\mathrm{a}+\mathrm{b}-)(0.6(0.3-0.8) \mathrm{mg} / \mathrm{dl})$ groups.

Table III shows the CA 19.9 distribution according to the Lewis phenotype. Interestingly $94.3 \%$ of patients with undetectable CA 19.9 (33 out of 35) had a Lewis-negative phenotype. Ninety-six percent of patients with detectable CA

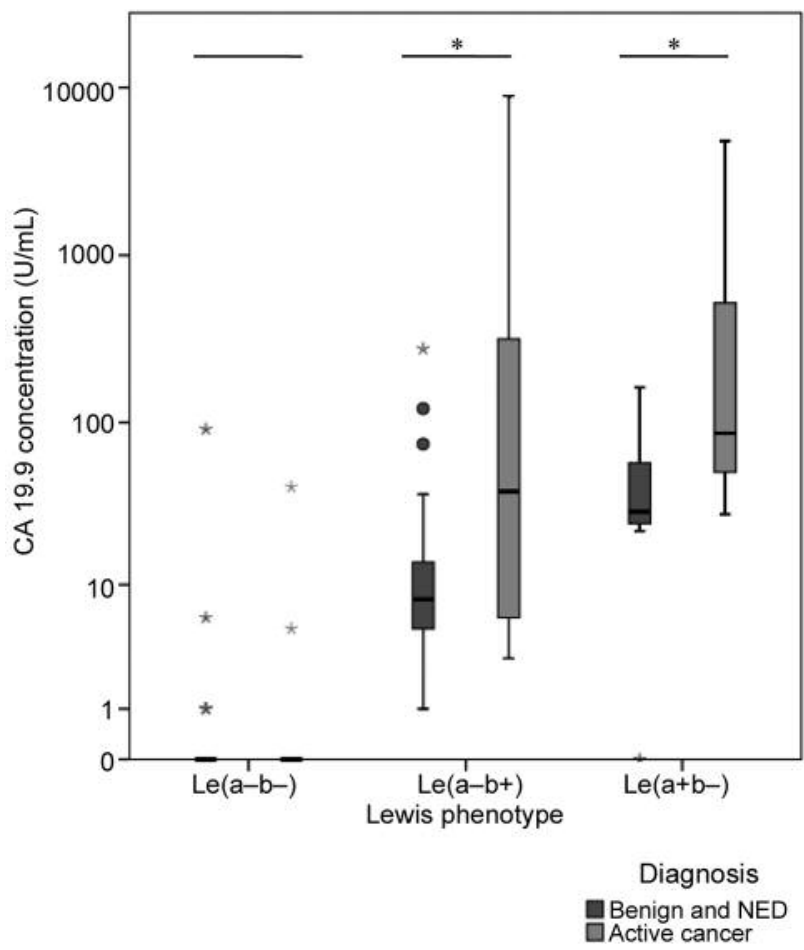

Figure 2. Box-plot of the CA 19.9 concentration depending on the diagnosis (benign disease and NED or active cancer) within the Lewis phenotype groups. NED: No evidence of disease. Non-active cancer group included patients with benign disease and NED patients. *p-Value $<0.05$.

19.9 levels had $\operatorname{Le}(\mathrm{a}-\mathrm{b}+)$ or $\operatorname{Le}(\mathrm{a}+\mathrm{b}-)$ phenotypes. In other words, $94.4 \%$ of patients with, $\mathrm{Le}(\mathrm{a}-\mathrm{b}-)$ patients had undetectable or very low CA 19.9 serum levels, and only 2 $(5.5 \%)$ patients had slightly high serum levels and advanced biliary tract tumours (41 and $91 \mathrm{U} / \mathrm{ml})$.

Similar results were obtained when serial dilutions of CA 19.9 serum samples were evaluated in 93patients as shown in Table IV. Serial CA 19.9 determinations were performed in $28 \mathrm{Le}(\mathrm{a}-\mathrm{b}-)$ patients (median 5, range $=2-19$ determinations) and in 26 (92.8\%) of them CA 19.9 was undetectable. In contrast, CA 19.9 was always detectable in 65 of 67 (97\%) patients with positive Le phenotype, including 47Le $(\mathrm{a}-\mathrm{b}+)$ patients and 18 patients with the Le $(a+b-)$ phenotype (Table IV).

\section{Discussion}

CA 19.9 has been suggested to help in diagnosis and therapy monitoring of gastrointestinal tumours, primarily of pancreatic cancer $(2-5,8-10)$. The sensitivity of this marker is high, even at the early stages, and differences according to tumour extension are quantitative. However, in the group 
Table II. Distribution of clinical data within Lewis phenotype groups.

\begin{tabular}{|c|c|c|c|}
\hline \multirow[b]{2}{*}{ Total of patients } & \multicolumn{3}{|c|}{ Lewis phenotype } \\
\hline & $\begin{array}{c}\mathrm{a}-\mathrm{b}- \\
36\end{array}$ & $\begin{array}{c}a-b+ \\
63\end{array}$ & $\begin{array}{c}a+b- \\
24\end{array}$ \\
\hline Active cancer & $14(38.9 \%)$ & $26(41.3 \%)$ & $13(54.2 \%)$ \\
\hline Pancreatic cancer & 4 & 8 & 7 \\
\hline Intestinal cancer & 2 & 2 & - \\
\hline Lung cancer & 4 & 4 & 2 \\
\hline Endometrial cancer & - & 2 & 1 \\
\hline Gastric cancer & - & 4 & - \\
\hline Others & 4 & 6 & 3 \\
\hline Total stage II-III & 4 & 11 & 5 \\
\hline Total stage IV & 10 & 15 & 8 \\
\hline CA 19.9 (median (interquartile range) & $0(0-0)$ & $45(6-357)$ & $86(48-1182)$ \\
\hline \multicolumn{4}{|l|}{ Non-active $*$} \\
\hline NED & $9(25.0 \%)$ & $16(25.4 \%)$ & $3(12.5 \%)$ \\
\hline CA 19.9 (median (interquartile range) & $0(0-1)$ & $9(5-16)$ & $25(22-n c)$ \\
\hline Benign & $13(36.1 \%)$ & $21(33.3 \%)$ & $8(33.3 \%)$ \\
\hline CA 19.9 (median (interquartile range) & $0(0-0)$ & $6(5-18)$ & $32(25-65)$ \\
\hline
\end{tabular}

NED: No evidence of disease; nc: not calculated. *Non-active cancer group included NED patients and patients with benign diseases.

Table III. Distribution of the Lewis phenotype within CA 19.9 concentration groups, in terms of the absolute value.

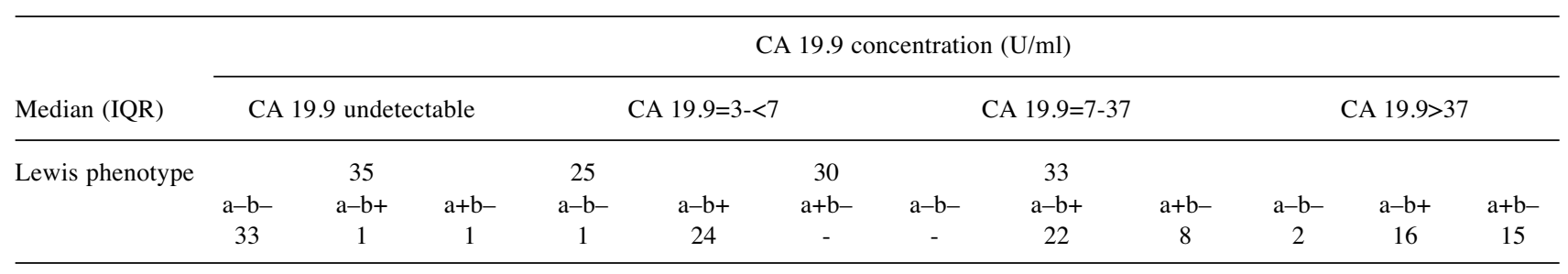

CA 19.9 range concentration is divided in four groups (undetectable, low range $3 \leq 7,7-37$ and $>37$ ), considering that the functional sensitivity is $3 \mathrm{U} / \mathrm{ml}$ and considering $37 \mathrm{U} / \mathrm{ml}$ to be the cut-off level.

Table IV. Serial determination of CA 19.9, subdivided according to the Lewis phenotype.

\begin{tabular}{|c|c|c|c|}
\hline \multirow[b]{2}{*}{ Total of patients } & \multicolumn{3}{|c|}{ Lewis phenotype } \\
\hline & $\begin{array}{c}\mathrm{a}-\mathrm{b}- \\
28\end{array}$ & $\begin{array}{c}a-b+ \\
47\end{array}$ & $\begin{array}{c}\mathrm{a}+\mathrm{b}- \\
18\end{array}$ \\
\hline \multicolumn{4}{|l|}{ Number of determinations } \\
\hline Always undetectable & $26(92.8 \%)$ & $1(2.1 \%)$ & - \\
\hline Always detectable & $1(3.6 \%)$ & $45(95.8 \%)$ & $18(100 \%)$ \\
\hline Both detectable and undetectable & $1(3.6 \%)$ & $1(2.1 \%)$ & - \\
\hline
\end{tabular}

of patients negative for CA 19.9, there were several patients that were unable to synthesize this antigen, namely, those with the Le(a-b-) phenotype $(15,18,20-22)$. These results were confirmed in our study, and a clear relationship between the CA 19.9 serum levels and the Le phenotype or tumour stage was observed. However, in our study, CA 19.9 serum levels were significantly higher in $\mathrm{Le}(\mathrm{a}+\mathrm{b}-)$ than in those with $\operatorname{Le}(\mathrm{a}-\mathrm{b}+)$ in both active cancer and other 
conditions, independent of the most common source of false positive results, namely, bilirubin concentrations. These unpublished data, should be confirmed in a study examining a large number of patients.

The absence of CA 19.9 release or synthesis in Lenegative patients implies that in CA 19.9-negative patients suspected to have cancer, the Le phenotype should be determined to avoid misinterpretations. However, the majority of laboratories do not determine the Le phenotype in routine samples, since it increases costs and delays and because clinicians will often only suggest cancer when the CA 19.9 is abnormally high. Our data clearly showed that $94.3 \%(33 / 35)$ of patients with undetectable CA 19.9 levels had the Le(a-b-) phenotype. Likewise, $91.7 \%$ of patients (33/36) with the Le(a-b-) phenotype had undetectable CA 19.9 serum levels, and 1 patient $(2.8 \%)$ had levels of this antigen that were near the analytical sensitivity. In summary, our results clearly suggest that undetectable CA 19.9 serum levels in patients suspicious of having pancreatic cancer should be evaluated carefully because the possibility of the Le(a-b-) phenotype is notably high.

Determination of CA 19.9 levels in serial serum samples confirmed the initial results indicating that ninety-three percent of patients (27/29) had undetectable CA 19.9 serum levels, and 96\% (26/27) of them were Le negative. Likewise, CA 19.9 levels in 26 of 28 patients with the Le-negative phenotype were always undetectable. These data raise the question whether it is necessary to perform serial CA 19.9 determinations in patients with undetectable levels when they are always negative, independently of tumour activity. If $10 \%-15 \%$ of the subjects are Le-negative and do not synthesize CA 19.9, its determination and use as a marker to follow-up these patients is meaningless. In 2015, 6713 analyses of CA 19.9 levels were performed in our laboratory, and in $9.13 \%$ of them CA 19.9 was not detected. Exclusion of these patients from follow-up will decrease cost, increase efficiency, and avoid misinterpretations.

It is surprising that 2 Le-negative patients with active pancreatic cancer or cholangiocarcinoma had detectable CA 19.9 serum levels (41 and $91 \mathrm{U} / \mathrm{ml}$ ). We repeated the Le phenotype evaluation, which was confirmed. It is interesting to observe that serial determinations of CA 19.9 in these patients showed that the changes in the levels of this tumour marker did not relate to tumour evolution. Hamada et al. (17) also detected CA 19.9 in a small number of patients who genetically lacked the Lewis enzyme. Several studies explained this paradox with the hypothesis that Lewisnegative patients can release a part of the protein, and certain antibodies used in the enzymatic immunoassay might detect them $(23,24)$. Another hypothesis would be that CA 19.9 positivity may derive from a cross-reaction of the antibodies used for CA 19.9 determination, as has been previously reported $(25,26)$. To reduce interference of cross-reactions within CA 19.9 analysis, serial dilutions of antigens or antibodies were performed, and these CA 19.9 levels were not demonstrated to be non-specific.

To conclude, CA 19.9 levels were related to the Lewis phenotype and status of the disease. Lewis-negative patients had undetectable levels of CA 19.9 in $91.7 \%$ of the cases in a serial determination, suggesting that this TM is not useful in diagnosis and follow-up of this group of patients. This result suggests that CA 19.9 analysis is meaningless in Lewis-negative patients with benign disease or cancer.

\section{Conflicts of Interest}

The Authors disclose no conflicts of interest.

\section{References}

1 Magnani JL, Nilsson B, Brockhaus M, Zopf D, Steplewski Z, Koprowski H, and Ginsburg V: A monoclonal antibody-defined antigen associated with gastrointestinal cancer is ganglioside containing sialylatedlacto-N-fucopentaose II. J Biol Chem 257: 14365-14369, 1982.

2 Molina V, Visa L, Conill C, Navarro S, Escudero JM, Auge JM, Filella X, Lopez-Boado MA, Ferrer J, Fernández-Cruz L and Molina R: CA 19-9 in pancreatic cancer: retrospective evaluation of patients with suspicion of pancreatic cancer. Tumour Biol 33: 799-807, 2012.

3 Duraker N, Hot S, Polat Y, Höbek A, Gençler N and Urhan N: CEA, CA 19-9, and Ca 125 in the differential diagnosis of benign and malignant pancreatic diseases with or without jaundice. J Surg Oncol 95: 142-147, 2007.

4 Filella X, Fuster J, Molina R, Grau JJ, García-Valdecasas JC, Grande L, Estape J and Ballesta AM: TAG-72, CA 19.9 and CEA as tumor markers in gastric cancer. Acta Oncol 33: 747-751, 1994.

5 Stieber P, Molina R, Gion M, Gressner A, Troalen F, Holdenrieder S, Auge JM, Zancan M, Wycislo M and Jarrige V: Alternative antibody for the detection of CA19-9 antigen: a European multicenter study for the evaluation of the analytical and clinical performance of the Access GI Monitor assay on the UniCelDx1 800 Immunoassay System. Clin Chem Lab Med 46: 600-611, 2008.

6 Molina R, Bosch X, Auge JM, Filella X, Escudero JM, Molina V, Solé M and López-Soto A: Utility of serum tumor markers as an aid in the differential diagnosis of patients with clinical suspicion of cancer and in patients with cancer of unknown primary site. Tumour Biol 33: 463-474, 2012.

7 Kondo N, Muramaki Y, Uemura K, Sudo T, HashimotoY, Sasaki $\mathrm{H}$ and Sueda T: Elevated perioperative serum CA 19-9 levels are independent predictors of poor survival in patients with resectable cholangiocarcinoma. J Surg Oncol 110: 422-429, 2014.

8 Molina R, Ojeda B, Filella X, Borras G, Jo J, Mas E, Lopez JJ and Ballesta A: A prospective study of tumor markers CA 125 and CA 19.9 in patients with epithelial ovarian carcinomas. Tumour Biol 13: 278-286, 1992.

9 Cherchi PL, Dessole S, Ruiu GA, Ambrosini G, Farina M, Capobianco G and Ambrosini A: The value of serum CA 125 and association CA 125/CA 19-9 in endometrial carcinoma. Eur J Gynaecol Oncol 20: 315-317, 1999. 
10 Molina R, Auge JM, Escudero JM, Marrades R, Viñolas N, Carcereny E, Carcereny E, Ramirez J and Filella X: Mucins CA 125, CA 19.9, CA 15.3 and TAG-72.3 as tumor markers in patients with lung cancer: comparison with CYFRA 21-1, CEA, SCC and NSE. Tumour Biol 29: 371-380, 2008.

11 Furuya N, Kawa S, Hasebe O, Tokoo M, Mukawa K, Maejima $\mathrm{S}$ and Oguchi H: Comparative study of CA 242 and CA19-9 in chronic pancreatitis. Br J Cancer 73: 372-376, 1996.

12 Barone D, Onetto M, Conio M, Paganuzzi M, Saccomanno S, Aste $\mathrm{H}$ and Pugliese V: CA 19-9 assay in patients with extrahepatic cholestatic jaundice. Int J Biol Markers 3: 95-100, 1988.

13 Peterli R, Meyer-Wyss B, Herzoq U and Tondelli P: CA 19-9 has no value as a tumor marker in obstructive jaundice. Schweiz Med Wochenschr 129: 77-79, 1999.

14 Akdoğan M, Saşmaz N, Kayhan B, Biyikoğlu I, Dişibeyaz S and Sahin B: Extraordinarily elevated CA 19-9 in benign conditions: a case report and review of the literature. Tumori 87: 337-339, 2001.

15 Tempero MA, Uchida E, Takasaki H, Burnett DA, Steplewski Z and Pour PM: Relationship of carbohydrate antigen 19-9 and Lewis antigens in pancreatic cancer. Cancer Res 47: 5501-5503, 1987.

16 Sturgeon CM, Duffy MJ, Stenman UH, Lilja H, Brünner N, Chan DW, Babaian R, Bast RC Jr, Dowell B, Esteva FJ, Haglund C, Harbeck N, Hayes DF, Holten-Andersen M, Klee GG, Lamerz R, Looijenga LH, Molina R, Nielsen HJ, Rittenhouse H, Semjonow A, Shih IM, Sibley P, Sölétormos G, Stephan C, Sokoll L, Hoffman BR and Diamandis EP: National Academy of Clinical Biochemistry laboratory medicine practice guidelines for use of tumor markers in testicular, prostate, colorectal, breast and ovarian cancers. Clin Chem 54: 11-79, 2008.

17 Hamada E, Taniguchi T, Baba S and Maekawa M: Investigation of unexpected serum CA 19-9 elevation in Lewis-negative cancer patients. Ann Clin Biochem 49: 266-272, 2012.

18 Von Rosen A, Linder S, Harmenberg U and Pegert S: Serum levels of CA 19-9 and CA 50 in relation to Lewis blood cell status in patients with malignant and benign pancreatic disease. Pancreas 8: 160-165, 1993.
19 Travis WD, Colby TV, Corrin B, Shimosato Y and Brambilla E: Histological typing of lung and pleural tumours. World Health Organization. International Histological Classification of Tumours, 3rd ed. Springer-Verlag, 1999.

20 Hanada H, Mugii S, Takeoka K, Maeda I, Watanabe M, Hidaka $\mathrm{Y}$ and Iwatani Y: A solution for distinguishing Le(a-b-) sera in CA19-9 assays using SphereLight 180 and Architect i2000 assays. Clin Chim Acta 413: 278-281, 2012.

21 Narimatsu H, Iwasaki H, Nakayama F, Ikehara Y, Kudo T, Nishihara S, Sugano K, Okura H, Fujita S and Hirohashi S: Lewis and secretor gene dosages affect CA19-9 and DU-PAN-2 serum levels in normal individuals and colorectal cancer patients. Cancer Res 58: 512-518, 1998.

22 Vestergaard EM, Hein HO, Meyer H, Grunnet N, Jørgensen J, Wolf $\mathrm{H}$ and Orntoft TF: Reference values and biological variation for tumor marker CA 19-9 in serum for different Lewis and secretor genotypes and evaluation of secretor and Lewis genotyping in a Caucasian population. Clin Chem 45(1): 54-61, 1999.

23 La'ulu SL and Roberts WL: Performance characteristics of five automated CA 19-9 assays. Am J Clin Pathol 127(3): 436-440, 2007.

24 Hotakainen K, Tanner P, Alfthan H, Haglund C and Stenman $\mathrm{UH}$ : Comparison of three immunoassays for CA 19-9. Clin Chim Acta 400(1-2): 123-127, 2009.

25 Berth M, Bosmans E, Everaert J, Dierick J, Schiettecatte J, Anckaert E and Delanghe J: Rheumatoid factor interference in the determination of carbohydrate antigen 19-9 (CA 19-9). Clin Chem Lab Med 44: 1137-1139, 2006.

26 Bjerner J: Human anti-immunoglobin antibodies interfering in immunometric assays. Scand J Clin Invest 65: 349-364, 2005.

Received August 26, 2018

Revised September 18, 2018

Accepted September 20, 2018 